\title{
"Passing" and the Politics of Deception: Transgender Bodies, Cisgender Aesthetics, and the Policing of Inconspicuous Marginal Identities
}

\author{
Thomas J Billard \\ Annenberg School for Communication \& Journalism, \\ University of Southern California \\ tbillard@usc.edu
}

October 8, 2018

\begin{abstract}
Billard raises important questions about the nature of "deception" and status of "deceiver," analyzing media discourses surrounding instances of transgender "passing." These discourses position transgender people as deceivers who live out their genders to seduce heterosexuals, scrutinizing their appearances for signs of their "true gender." Contradictorily, the successful attainment of cisgender aesthetics deemed "passing" legitimates a transgender person's gender identity, but also renders them more malicious in their deception. As such, media discourses surrounding transgender people who "pass" justify punishment for their deception through violence. In this chapter, Billard explores these tensions, challenging the application of the label "deception" by the social majority to those of marginal identities, particularly inconspicuous ones, as it serves to delegitimate authentic identities and police the boundaries of social hierarchies.
\end{abstract}

Keywords transgender, passing, violence, deception, identity

Cite as Billard, Thomas J. "Passing' and the Politics of Deception: Transgender Bodies, Cisgender Aesthetics, and the Policing of Inconspicuous Marginal Identities." In The Palgrave Handbook of Deceptive Communication, edited by Tony Docan-Morgan. New York, NY: Palgrave Macmillan, in press. 


\section{Introduction}

In May 2016, lawyers, academics, and activists gathered in London for the TransJustice conference, a workshop cosponsored by Birkbeck, University of London and City University London. The conference focused on legal issues facing transgender Britons, particularly in the domain of criminal justice. Among the issues discussed were the troubling implications of the 2003 Sexual Offences Act for transgender individuals. After extensive discussion and debate, the gathered experts reached the conclusion that, as currently written, the law could classify those who do not disclose their gender assigned at birth - or, as Goffman (1963) would put it, their discreditable stigma - prior to engaging in sexual intercourse as rapists (Fae, 2016; Sims, 2016). Thus, transgender individuals living out their authentic gender identities could become criminal deception when cisgender (i.e., non-transgender) individuals are not aware of the genders transgender people were assigned at birth.

This policy, while shocking in its own right, is merely reflective of broader cultural discourses about transgender identity and deception circulated in media narratives of transgender lives (BarkerPlummer, 2013; Halberstam, 2001; MacKenzie \& Marcel, 2009; Sloop, 2000; Squires \& Brouwer, 2002; Willox, 2003) and enacted in interpersonal interactions between cis- and transgender people every day (Schilt \& Westbrook, 2009). These discourses position transgender people as deceivers who live out their genders for the purpose of seducing cisgender heterosexuals (Schilt \& Westbrook, 2009; Squires \& Brouwer, 2002), scrutinizing their appearances for signs of their "true" (i.e., assigned at birth) gender (Billard, 2016b; Rogers, 1992; Sloop, 2000). As such, these discourses delegitimate transgender identities by implicitly (and sometimes explicitly) suggesting that transgender identities are falsehoods that conceal the truth of "biological gender."

Central to these discourses of deception is the concept of "passing." Those transgender people who show no clear signs of the gender they were assigned at birth "pass" (as cisgender), while those who do show signs fail to "pass." Contradictorily, the successful attainment of cisgender aesthetics deemed "passing" legitimates a transgender person's claim to their gender identity (Billard, 2016b; Booth, 2015), but also renders them more malicious in their deception. In the words of Jack Halberstam (2001), the customary narrative of transgender life "recasts the act of passing as deception, dishonesty, and fraud" (p. 14). Consequently, discourses surrounding transgender people who "pass" justify punishment for their deception, whether through violence and murder (MacKenzie \& Marcel, 2009) or through incarceration (as with the Sexual Offences Act).

Transgender passing thus raises important questions about the nature of "deception" and the status of "deceiver," as well as about where authenticity and honesty diverge from one another. This chapter explores those tensions, challenging the application of the label of "deception" by the social majority to those of marginal identities, particularly inconspicuous ones, as it serves to delegitimate authentic identities and police the boundaries of social hierarchies. To do so, I first review the concept of "passing" as it has been articulated in both humanistic and social scientific literatures, before turning to scholarship on transgender passing in particular and the ways in which transgender identities are aesthetically evaluated. I then analyze media discourses of transgender deception and how these discourses legitimate anti-transgender violence. Finally, I discuss the ways in which the concept of deception polices marginal identities more generally before concluding with some of the implications of this argument.

\section{Conceptualizing "Passing"}

Passing has been defined in widely varied ways, and from different disciplinary and ideological perspectives. While certain scholars argue that passing represents a rejection of socially imposed identities and the construction of new ones through constant performance (Caughie, 2005), others 
view passing as more utilitarian in function, namely to ensure the survival of the one who passes (Ahmed, 1999; Hobbs, 2014; Moriel, 2005). This latter perspective further, and necessarily, implies that passing occurs only when someone from a marginal or oppressed social group crosses over into the dominant or privileged group (Moriel, 2005; Snorton, 2009). Other perspectives are less restricted, maintaining that passing challenges assumptions of immutable, physiologically based categories by demonstrating the insufficiencies of physiological evidence in accurate social categorization, regardless of the direction in which the passing occurs (Moynihan, 2010). ${ }^{1}$ Yet each definition generally converges on a core notion of passing articulated quite clearly by Liora Moriel (2005): "a person from group A simply self-identifies as belonging to group B (and vice versa), is accepted as a member of the other group, and occupies that identity position without detection" (p. 177). It is in moments of detection, however, that discourses of deception arise.

The concept of passing in the United States finds it origins in racial passing, and particularly in concerns about Black Americans passing undetected as White and/or freedmen in the eighteenth and nineteenth centuries (Hobbs, 2014). Cultural tensions around the status of race categorizations were high, as runaway slaves with light complexions evaded recapture and as rural Blacks moved into cosmopolitan environments to seek opportunities for economic and social advancement by passing for White (Hobbs, 2014). The resultant cultural panic manifested in legal battles, as courts sought to establish criteria by which to evaluate citizen's "official" racial identities (Gross, 1998). In the twentieth and twenty-first centuries, however, "passing" has been increasingly considered in contexts of class (e.g., Foster, 2005; Moriel, 2005), sexuality (e.g., Leary, 2012; McCune, 2014), and sex and gender (Caughie, 2005; Halberstam, 2001; Moynihan, 2010; Snorton, 2009; Squires \& Brouwer, 2002).

Recent research on passing has occurred largely in the humanities, where it has been discussed in terms of performative identities and the transgression of social boundaries (Ahmed, 1999; see Ginsberg, 1996; McCune, 2014; Moriel, 2005; Rottenberg, 2003). As Sara Ahmed (1999) noted, this work generally positions passing as "a radical and transgressive practice that serves to destabilize and traverse the system of knowledge and vision upon which subjectivity and identity precariously rests" (p. 88). Moreover, as Elaine Ginsberg (1996) wrote, "passing is about identities: their creation or imposition, their adoption or rejection, their accompanying rewards or penalties" (p. 2). This line of inquiry has primarily focused on narratives, analyzing fictional texts as well as biographies for evidence of how social categories are constructed, enforced, challenged, and recuperated (Halberstam, 2001; McCune, 2014; Moriel, 2005; Moynihan, 2010; Rottenberg, 2003).

Within the social scientific literature, however, sociologists have developed a robust line of inquiry on passing, beginning with Erving Goffman's work on stigma and stigma management. From Goffman's (1963) perspective, passing is about "the management of undisclosed discrediting information about the self" (p. 42). That is, for an individual who has an invisible stigma known only to themselves (whether in the form of a disability or stigmatized social identity, such as homosexuality), said individual "passes" when others lack any "discrediting information" - information that would reveal the stigma - about them. This passing may be incidental, rather than intentional, or it may be a deliberate strategy on the part of the individual who wishes to maintain their social status by concealing their stigma. Where it concerns the latter, Goffman discussed the stigmatized individuals' control of social information, whether that information is visual or behavioral.

Thomas Kando (1972) applied Goffman's model of passing and stigma management to transsexuals, arguing that transsexualism is discreditable, rather than discrediting - which is to say, the stigma of transsexual identity can be discovered, but is not necessarily apparent without disclosure. As such, passing, as the state of non-discovery, can be seen as a method of stigma management (Kando, 1972, p. 477). Yet the transsexual's passing, as Kando noted, is not achieved through a singular act of (surgical) transition, but through a continuing process of gender. As Candace 
West and Don Zimmerman (1987) argued, gender is always a "routine, methodical, and recurring accomplishment" (p. 126), and that includes in contexts of gender passing.

The truth of this argument is seen in one of the many points made by Suzanne Kessler and Wendy McKenna (1978) in their ethnomethodological investigation of gender: genitalia, which we usually presume to be the site of an individual's gender, are generally concealed from public view in daily life, and yet we perceive people (often accurately) as being one of two genders based on external social cues, such as clothing, physical attributes, and comportment. In this sense, everyone "passes" as their gender, as the "truths" of our anatomies are concealed from others' inspection (Rogers, 1992; c.f. Zimmerman, 1992). ${ }^{2}$

In perhaps the most seminal investigation of transgender passing, Harold Garfinkel (1967) discussed how Agnes, a young transsexual woman, "achieved" her feminine gender - thus "passing"through the management of social presentation and avoidance of situations which presented "the possibility of detection and ruin" (p. 137). While some scholars have focused their attention on Agnes' need to gain "cultural knowledge of how [womanhood] was to be done" (Wickes \& Emmison, 2007 , p. 314) - assuming she did not already have this knowledge - the instances of stigma management described by Garfinkel nearly all centered on her physical appearance and/or the physical manifestations of social performance. For example, Garfinkel (1967) recounted Agnes' concern over whether there would be an assured private space for her to change out of her wet bathing suit on a day at the beach with friends. In another instance, he described Agnes' initial false sexual modesty, which she performed to prevent her boyfriend discovering she had male genitalia. Thus, the management of transgender stigma, even where social performances of gender are concerned, center in large part on visual components of passing.

\section{Transgender Passing and Cisgender Aesthetics}

Because transgender individuals' "passing" is fundamentally visual in nature ${ }^{3}$ and because passing more generally refers to an individual's undetected membership in a social group into which they were not assigned at birth, passing for transgender individuals necessarily implies the attainment of cisgender aesthetics. That is, for a transgender person to pass, they must appear to a stranger to "look cisgender." Such was the achievement of Agnes. That is not to say that a transgender person must necessarily appear conventionally attractive to pass, for, as Mary Rogers (1992) argued, "[t]hat Agnes apparently met cultural standards of female attractiveness is far less relevant than that she exhibited no physical characteristics visibly jeopardizing her appearance as a 'normal' female" (p. 182). Thus, the acceptably gendered appearance of a transgender individual is of central concern to their passing.

The attainment of cisgender aesthetics deemed "passing" is not necessarily considered a desirable achievement, however. Rather, there is contentious debate among transgender theorists and activists about whether the desire to pass is "good" or "bad." In her argument for a shift toward "posttranssexualism," Sandy Stone (1994) wrote, "[t]he essence of transsexualism is the act of passing" (p. 168), but the rejection of passing - the deliberate choice to not pass - represents a more politically liberated transgender identity that we might call "posttranssexual." Likewise, Kate Bornstein (1995) argued that passing "becomes the outward manifestation of shame and capitulation. Passing becomes silence. Passing becomes invisibility. Passing becomes lies. Passing becomes self-denial" (p. 125). Yet, as Katrina Roen (2002) remarked, this perspective, while important for its points about regimes of gender enforcement, comes "perilously close to accusing passing transsexuals of having false consciousness" (p. 508). Indeed, passing is often considered a desirable achievement among transgender communities, while those who expend too little effort at passing are judged (Roen, 2002). Moreover, for many transgender people, passing does not represent illusion or concealment, 
but self-actualization and psychic realness (Halberstam, 2001; Snorton, 2009).

But regardless of any moral judgments that could be debated concerning it, we must acknowledge the centrality of passing to transgender existence, particularly as mediated to the public. I have discussed elsewhere how news media representations of transgender individuals focus on the successful attainment of cisgender aesthetics in their discussions of transgender identity. As I argued, "Journalists weave aesthetic evaluations into their storytelling, using these evaluations to judge the legitimacy and the quality of the transgender person's identity" (Billard, 2016b). John Sloop (2000) argued similarly in his analysis of coverage of the murder of Brandon Teena, who journalists described as an "ideal man" because of his handsome "male" appearance. This reliance on aesthetic evaluations of transgender identity is not unique to news media however. For example, E. Tristan Booth (2015) found that in the narration of televised documentaries, the gender identities of transgender individuals were only acknowledged after surgical alteration - after their appearances had been made to conform to cisgender standards.

Even from a normative perspective, this reliance on cisgender aesthetic achievement as a marker of successful gender is problematic. As I have written previously,

In evaluating transgender people aesthetically, journalists suggest to their readers that aesthetics are the primary determinant of the legitimacy and the quality of a transgender person's gender identity, and reinforce the idea that gender identity is purely aesthetic, rather than a complex set of social characteristics and self-identifications (Billard, 2016b).

Moreover, this reduction of the legitimacy and the quality of transgender identity to a transgender individual's success at passing necessarily sustains the assumption that cisgender identity is normatively "better," and that all other gender identities are mere facsimiles of the "natural" genders of cisgender men and women (Billard, 2016b).

Furthermore, in considering passing as a metric of successful gender achievement, we must consider the differences in transition process between transgender men and transgender women. As Booth (2015) noted, "[b]ecause testosterone produces facial hair, trans men are usually perceived as male [i.e., pass] without facial surgery, whereas for trans women, estrogen does not produce an equivalent marker of female-bodiedness, nor does it reduce one's height" (p. 124). Thus, the use of passing as criteria for authentic gender identity disproportionately acknowledges masculine gender identities while perpetuating the devaluation of feminine identities (see also Schilt \& Westbrook, 2009).

\section{Media Discourses of Deception and Anti-Transgender Vi- olence}

Perhaps the most damaging cultural work performed by aesthetic evaluations of transgender identities is their supporting role in media discourses of deception. As many scholars have noted, passing is often seen as an act of deception - as the perpetration of an identity-based fraud (e.g., Caughie, 2005; Halberstam, 2001; McCune, 2014). Transgender individuals who pass are, in particular, often described as "double, duplicitous, deceptive" (Halberstam, 2001, p. 24), or as perpetrating a "charade' or 'masquerade"" (Ginsberg, 1996, p. 16). Even where those labels have not been explicitly applied, as Sinad Moynihan (2010) has remarked, "the metaphors of concealment, subterfuge and deception that have historically characterised passing are still pervasive" (p. 2). This thus casts a transgender individual who passes as "a predator who successfully preys on others by keeping them from the truth" (Sloop, 2000, p. 170).

Admittedly, transgender individuals who fail to pass cannot escape discourses of deception either. There is a passing double bind whereby the transgender person who passes is an insidiously successful 
deceiver, while the transgender person who does not pass is a monstrously unsuccessful deceiver. As Gordene MacKenzie and Mary Marcel (2009) noted, transgender women in particular who do not pass are depicted as "men in dresses" who deserve "disciplinary violence" and transgender women who do pass are depicted as tricksters who deserve the rage of their "victims" (p. 83). ${ }^{4}$ Nonetheless, the "deception" of passing is by far the greater crime in these narratives, as transgender people who pass are regarded as far more insidious and discussed in far more defamatory ways.

A wide body of literature has documented discourses of deception in the coverage of transgender murder victims (e.g., Barker-Plummer, 2013; Bettcher, 2007; MacKenzie \& Marcel, 2009; Schilt \& Westbrook, 2009; Sloop, 2000; Squires \& Brouwer, 2002; Willox, 2003). ${ }^{5}$ Early work identifying these discourses focused on the murder of Brandon Teena, a transgender man who was murdered in 1993 by two male acquaintances who had discovered his sex assigned at birth, mere weeks after reporting his rape by them (Sloop, 2000; Squires \& Brouwer, 2002; Willox, 2003). Subsequent discourses in both mainstream and marginal media insisted Brandon was a woman and therefore a "lesbian deceiver" (Squires \& Brouwer, 2002, p. 301) who "pass[ed] herself off as a boy" (Willox, 2003, p. 415). In the words of MacKenzie and Marcel (2009), applying this "deception narrative" to Brandon's story "privileges [his] female anatomy as the 'true' source of his gender identity, rather than his own consistent practice of living as a man and seeing himself as male" (p. 79), thereby delegitimating his claim to his masculine gender.

Bernadette Barker-Plummer (2013) noted similar narratives in coverage of the murder of Gwen Araujo, a feminine-passing non-binary transgender person whom news media claimed had "tricked" hir $^{6}$ murderers into sexual contact by "pretending to be a woman whilst 'really' being a man" (p. 714; see also Bettcher, 2007)..$^{7}$ Indeed, across a wide range of coverage of transgender murder victims, violence is identified as "a response to actual or perceived deception of the perpetrator by the transgender person" (Schilt \& Westbrook, 2009, p. 446). As Barker-Plummer (2013) remarked, this causal attribution of violence to deception implies that "transgender identity is in itself a provocation" (p. 715). And this implication is drawn out more fully in these murderers' defense that they simply "panicked" at the realization they had been deceived (Barker-Plummer, 2013; Bettcher, 2007; MacKenzie \& Marcel, 2009).

"Trans panic" defenses - the name given to the argument that a transgender person's murderer acted in the heat of passion at discovering their presumed-cisgender sexual partner was actually transgender, and should therefore not be held responsible for their crime - have been widely used in criminal cases (Lee \& Kwan, 2014; Tilleman, 2010; Wodda \& Panfil, 2015). However, these defenses have not only been deployed in the courtroom, but also echoed in media coverage of the cases (Barker-Plummer, 2013). In fact, Kristen Schilt and Laurel Westbrook (2009) found that $56 \%$ of stories covering the murder of transgender women advanced the narrative of the panicked perpetrator. As they write, "[t]he belief that gender deception in a sexual relationship would result in fatal violence is so culturally resonant that, even in cases where there is evidence that the perpetrator knew the victim was transgender prior to the sexual act, many people involved in the case, including journalists and police officers, still use the deception frame" (Schilt \& Westbrook, 2009, p. 457; see also MacKenzie \& Marcel, 2009).

This defense of the violent perpetrators' actions in turn legitimates the use of violence against transgender people. Building off the narrative of deception, the trans panic defense suggests that because the transgender victim deliberately withheld their "true gender" (Schilt \& Westbrook, 2009; Sloop, 2000), they were the true wrongdoer. In the words of Talia Mae Bettcher (2007), "victims of transphobic violence can be subject to blame shifting through accusations of deception" (p. 47). As such, the perpetrators are absolved (morally) of their crime and their use of violence is "justified" in such a way that anti-transgender violence at large is dismissed as deserved. As transgressors against truth through deception by successfully passing, transgender people, this discourse concludes, deserve 
their punishment.

\section{Against "Deception"}

The core function of these discourses of deception is the policing of identities - the maintenance of the boundaries that separate levels of social hierarchy and the delegitimation of claims to "new" identities that move individuals out of stigmatized ones. And, particularly in the transgender context, these discourses serve to insulate those cisgender individuals higher up in the social hierarchy from the "tainting" influence of transgender individuals' stigma. As Schilt and Westbrook (2009) discussed, framing transgender lives as "deceptive" works to protect the heterosexuality of the individuals who have sexual(ized) encounters with them; the man who slept with or hit on a transgender woman is truly straight because he was merely "deceived" by her passing into thinking she was a "natural" woman. Discourses of deception then excuse the man's "homosexual" behavior and blame (and justify punishment of) the transgender woman for dragging down his place in the social hierarchy.

While discourses of deception are particularly pertinent in the context of transgender passing, they do not operate solely in this sphere. Rather, analyzing how these discourses operate in the transgender context can further inform us about how discourses of deception operate in contexts of passing more broadly. For instance, applying the label of "deception" to transgender passing serves to exclude transgender women from the broader category of womanhood and to exclude transgender men from the category of manhood. Whereas the act(s) of passing communicate clearly the transgender person's membership in their self-determined gender category, calling these acts "deceptive" recasts their membership as "trespassing." As Ginsberg (1996) wrote of racial passing, "[a]s the term metaphorically implies, such an individual crossed or passed through a racial line or boundary - indeed trespassed - to assume a new identity" (p. 3; emphasis in the original). Kimberlyn Leary's (1999) definition of passing as a marginalized person's masquerade performed "in order to enjoy the privileges afforded to the dominant group" (p. 85) further supports this notion. The passing person thus becomes an invader of the dominant group who passes into the group to exploit the benefits of membership. ${ }^{8}$

These narratives further work to cast the identities of passing people as inauthentic ones. People who pass are, in the words of Halberstam (2001), "excluded from the domain of the real" (p. 17) and their identities are rearticulated by those in the dominant group as mere appropriations of "realness." Aesthetic evaluations of passing play a role in this, as these evaluations contrast "attainment" against "aspiration," implicitly communicating that the "attained" identity is a replica (of whatever quality) of the "aspirational" identity in the same way that a replica Monet might be compared against its original (Billard, 2016b). When such comparisons circulate in media narratives of passing, passing identities will necessarily be represented as inauthentic performances of the identities of those assigned into the social category into which one has passed.

At their core, both in the transgender context and more broadly, discourses of deception work to confine those who pass to their pre-passing state of discredited stigmatization. As Ginsberg (1996) neatly summarized it, passing permits stigmatized individuals to conceal their stigma, "escaping the insubordination and oppression accompanying one identity and accessing the privileges and status of the other" (p. 3). However, because, in the words of Squires and Brouwer (2002), "[d]ominant groups and institutions desire the ability to survey and evaluate all subordinates with ease, thereby ensuring knowledge and readiness" (p. 287), passing out of subordination must be punished. Such is the function of discourses of deception: public shaming and the justification of punishment through violence. As one salient example, Ahmed (1999) cited Nella Larsen's Passing, in which the main character, Clare, a black woman who passes as white, is "exposed" as a black woman and summarily killed. As Ahmed (1999) noted, "[s]uch a literalized punishment restores the narrative to its rightful 
order" (p. 91). Because a person with a stigmatized identity attempted to escape the plight of their stigma by passing, they were punished.

This then begs a final question of what a legitimating alternative discourse surrounding passing would be. I echo the sentiments of C. Riley Snorton (2009) in calling for interpretations of passing that focus not on the challenges passing poses to dominant groups' mechanisms of social control or the maintenance of social hierarchies, but rather on the psychic role of passing and its power to enable passing individuals' self-actualization. In Snorton's (2009) words, "passing is not simply a question of how one is read but includes an agential power of affirming one's own reading of self. Definitions of passing therefore must also include its psychological function, that is, that it brings one's 'self' into view" (p. 87). Thus, in turning away from understandings of passing as a deceitful practice, we affirm the agency of those who pass to construct legitimate and authentic identities.

\section{Conclusion}

As I have demonstrated throughout this chapter, the label of "deception" is not a neutral marker of dishonesty or fraud. Rather, it is a socially fraught term used by the dominant group to discriminate between the legitimated and the delegitimated, the authenticated and the inauthenticated, the "righteous" and the "wicked." And as a power held by the dominant group, application of the label of "deception" serves to police the boundaries established around those lower in the social hierarchy, to maintain their subordination. In the context of transgender passing, discourses of "deception" serve to constrict transgender agency in self-identification, to delegitimate transgender identity claims, and to reinforce the stigmatization of transgender identities.

Media discourses of transgender life portray transgender individuals as deceivers whose identities are often ruses by which to "trick" cisgender heterosexuals into homosexual behavior (BarkerPlummer, 2013; Bettcher, 2007; MacKenzie \& Marcel, 2009; Schilt \& Westbrook, 2009). Yet, even in the few instances in which deception narratives do not focus on sexual enticement, these narratives still suggest that transgender individuals' identities are artificial and that their "dishonesty" reflects on their poor moral character (Sloop, 2000). These discourses of deception follow directly from instances of "passing," however, as individuals who "pass" as cisgender have "deceived" others into ignorance of their sex assigned at birth. While in other instances successful passing legitimates transgender individuals' claims to their gender identities (Billard, 2016b; Booth, 2015), where discourses of deception are circulated their passing becomes evidence of the insidiousness of their deception. And this insidiousness, in turn, justifies the (often murderous) violence committed against them (Bettcher, 2007).

As such, the label of "deception" and the discourses that surround its use delegitimate authentic transgender identities and regulate the divisions in social hierarchy between the transgender marginalized and the cisgender dominant. This regulation (re)establishes transgender individuals as "lesser" and ensures that they cannot escape their stigmatization by passing as a "natural" member of their self-identified gender. Moreover, such regulation criminalizes transgender passing in much the same way that the passing of Blacks as White has been criminalized (Squires \& Brouwer, 2002), and for much the same reasons: Members of the dominant group feel entitled to inconspicuous marginalized individuals' "discrediting stigma" so that they can enforce existing regimes of social control. Those who successfully conceal this stigma are thus punished for attempting to escape the marginalization of their stigma, which the dominant group regards as the natural and necessary state of the subjugated.

The ultimate consequence of these discourses of deception, as repeatedly mentioned, is the delegitimation of transgender identities. This delegitimation may manifest is social attitudes both toward transgender individuals (e.g., Nagoshi et al., 2008) and toward transgender rights (e.g., Miller et al., 
2017), and it is apparent in public political debate over transgender policy (Billard, 2016a). Moreover, we see clear concretization of these discourses into social policy, such as in the Sexual Offences Act of 2003. We further see these discourses echoed in court cases (Lee \& Kwan, 2014; Tilleman, 2010; Wodda \& Panfil, 2015) and observe their impact on policing practices (Grant et al., 2011; James et al., 2016; Moran \& Sharpe, 2004). Thus, the significance of these discourses of deception is not merely ideological, but practical, as they influence the state of transgender acceptance both socially and politically.

Finally, discourses of deception legitimate anti-transgender violence, which is rampant not only in Western contexts, but globally (Kidd \& Witten, 2007; Stotzer, 2009). In her work on media violence, Sandra Ball-Rokeach $(1971,2001)$ has suggested that the greatest effect media has in the domain of violence is inducing the public to accept certain forms of violence as acceptable and legitimate (e.g., military, police) and reject others as unacceptable and illegitimate (e.g., civil unrest), which ultimately supports the status quo. As such, the great practical danger of how media discourses of transgender passing excuse anti-transgender violence is that it may produce in audiences the opinion that violence against transgender people should be accepted because it is justified, thereby reifying a status quo in which the lives of transgender people not only have no value, but are also regarded as unworthy of the basic right to safety and security. While we currently lack empirical evidence to demonstrate this effect, discourses of deception surrounding transgender passing are firmly established, and are likely operating already.

\section{Notes}

\footnotetext{
${ }^{1}$ It is important to note, however, as Ahmed (1999) did, that passing from a marginal group into the dominant group implies very different structural power relations than passing in the reverse direction.

${ }^{2}$ The "passing" of cisgender individ]uals is of course, as Zimmerman (1992) noted in his critique of Rogers (1992), not truly passing, but merely "doing gender." However, the parallel between transgender passing and cisgender "doing gender" productively highlights the ways in which transgender passing is constituted by the successful "doing" of gender.

${ }^{3}$ Of course, other sensory elements of gender presentation and perception, such as vocal pitch and intonation (e.g., Hancock \& Garabedian, 2013; Hancock, Colton, \& Douglas, 2014; King, Brown, \& McCrea, 2012), are key to transgender individuals' passing. However, discussion of these elements falls outside the scope of the present analysis, and their significance is less frequently discussed in both academic literature and popular media discourse than that of visual passing.

${ }^{4}$ Although these discourses are, in many instances, applied to transgender men, it is worth noting that they are disproportionately applied to transgender women (MacKenzie \& Marcel, 2009; Schilt \& Westbrook, 2009; Westbrook \& Schilt, 2014).

${ }^{5}$ While news stories covering the murder of transgender individuals have been the subject of most media scholarship on transgender issues, such stories actually comprise only $14 \%$ of all national transgender news coverage (Billard, 2016c). However, these stories contain the most egregious forms of delegitimization of transgender issues and identities, and are thus a subject of great academic interest. Moreover, these stories may, as MacKenzie and Marcel (2009) suggested, circulate more frequently in local, rather than national, transgender news coverage.

${ }^{6}$ Hir is a gender-neutral pronoun and Gwen's preferred pronoun. See Barker-Plummer (2013) for a more thorough discussion of hir pronoun preferences.

${ }^{7}$ Discourses of deception, while applied broadly to transgender people, are more frequently and more egregiously applied in sexualized contexts. As Schilt and Westbrook (2009) remarked, it is in sexualized spaces that gender identities become contentious, and cisgender individuals who are confronted with transgender identities in sexualized contexts deploy discourses that "regender" transgender people to the sex they were assigned at birth in order to protect and maintain the "heterosexual matrix" (pp. 450-451).

${ }^{8}$ For an example of radical feminist work that advances this shocking notion in the context of transgender identity, see Raymond (1979). For a start to critiques of this argument, see Riddell (2006), Serano (2007), and Stone (1994).
} 


\section{References}

Ahmed, S. (1999). "She'll wake up one of these days and find she's turned into a nigger": Passing through hybridity." Theory, Culture \&3 Society, 16(2), 87-106.

Ball-Rokeach, S. J. (1971). The legitimation of violence. In J. F. Short, Jr. \& M. E. Wolfgang (Eds.), Collective violence (pp. 100-111). Chicago, IL: Aldine.

Ball-Rokeach, S. J. (2001). The politics of studying media violence: Reflections 30 years after the Violence Commission. Mass Communication and Society, 4(1), 3-18.

Barker-Plummer, B. (2013). Fixing Gwen: News and the mediation of (trans)gender challenges. Feminist Media Studies, 13(4), 710-724.

Bettcher, T. M. (2007). Evil deceivers and make-believers: On transphobic violence and the politics of illusion. Hypatia, 22(3), 43-65.

Billard, T. J. (2016a, September). Constructing transgender identity in restroom-related policy debates. Paper presented at the annual meeting of the American Political Science Association, Philadelphia, PA.

Billard, T. J. (2016b, June). The transgender body as artistic creation: Journalists' aesthetic evaluations of transgender identity. Paper presented at the annual meeting of the International Communication Association, Fukuoka, Japan.

Billard, T. J. (2016c). Writing in the margins: Mainstream news media representations of transgenderism. International Journal of Communication 10, 4193-4218.

Booth, E. T. (2015). The provisional acknowledgment of identity claims in televised documentary. In L. G. Spencer \& J. C. Capuzza (Eds.), Transgender communication studies: Histories, trends, and trajectories (pp. 111-126). Lanham, MD: Lexington Books.

Bornstein, K. (1995). Gender outlaw: On men, women, and the rest of us. New York, NY: Vintage.

Caughie, P. L. (2005). Passing as modernism. Modernism/Modernity, 12(3), 385-406.

Fae, J. (2016, June 1). Trans people face jail for rape if they have sex without sharing their gender history: Why even a kiss can see trans people branded as sex criminals. Gay Star News. Retrieved from http://gaystarnews.com/article/trans-people-face-jail-rape-sex-without-sharinggender-history/

Foster, G. A. (2005). Class-passing: Social mobility in film and popular culture. Carbondale, IL: Southern Illinois University Press.

Garfinkel, H. (1967). Studies in ethnomethodology. Eaglewood Cliffs, NJ: Prentice-Hall.

Ginsberg, E. K. (1996). The politics of passing. In E. K. Ginsberg (Ed.), Passing and the fictions of identity (pp. 1-18). Durham, NC: Duke University Press.

Goffman, E. (1986). Stigma: Notes on the management of spoiled identity. New York, NY: Simon \& Schuster.

Grant, J. M., Mottet, L. A., Tanis, J., Harrison, J., Herman, J. L., \& Keisling, M. (2011). Injustice at every turn: A report of the National Transgender Discrimination Survey. Washington, DC: National Center for Transgender Equality and National Gay and Lesbian Task Force.

Gross, A. J. (1998). Litigating whiteness: Trials of racial determination in the nineteenth-century South. Yale Law Journal, 108(1), 109-188.

Halberstam, J. (2001). Telling tales: Brandon Teena, Billy Tipton, and transgender biography. In M. C. Snchez \& L. Schlossberg (Eds.), Passing: Identity and interpretation in sexuality, race, and religion (pp. 13-37). New York, NY: New York University Press.

Hancock, A. B., \& Garabedian, L. M. (2013). Transgender voice and communication treatment: A retrospective chart review of 25 cases. International Journal of Language 83 Communication Disorders, 48(1), 54-65.

Hancock, A., Colton, L., \& Douglas, F. (2014). Intonation and gender perception: Applications for transgender speakers. Journal of Voice, 28(2), 203-209. 
Hobbs, A. (2014). A chosen exile: A history of racial passing in American life. Cambridge, MA: Harvard University Press.

James, S. E., Herman, J. L., Rankin, S., Keisling, M., Mottet, L., \& Anafi, M. (2016). The report of the 2015 U.S. Transgender Survey. Washington, DC: National Center for Transgender Equality.

Kando, T. (1972). Passing and stigma management: The case of the transsexual. The Sociological Quarterly, 13(4), 475-483.

Kessler, S., \& McKenna, W. (1978). Gender: An ethnomethodological approach. New York, NY: Wiley.

Kidd, J. D., \& Witten, T. M. (2007). Transgender and transsexual identities: The next strange fruit - hate crimes, violence and genocide against the global trans-communities. Journal of Hate Studies, 6(1), 31-64.

King, R. S., Brown, G. R., \& McCrea, C. R. (2012). Voice parameters that result in identification or misidentification of biological gender in male-to-female transgender veterans. International Journal of Transgenderism, 13(3), 117-130.

Leary, K. (2012). Passing, posing, and "keeping it real." In L. Aron \& A. Harris (Eds.), Relational psychoanalysis (Vol. 4, pp. 31-44). New York, NY: Routledge.

Lee, C., \& Kwan, P. (2014). The trans panic defense: Masculinity, heteronormativity, and the murder of transgender women. Hastings Law Journal, 66 (1), 77-132.

MacKenzie, G., \& Marcel, M. (2009). Media coverage of the murder of U.S. transwomen of color. In L. M. Cuklanz \& S. Moorti (Eds.), Local violence, global media: Feminist analyses of gendered representations (pp. 79-106). New York, NY: Peter Lang.

McCune, J. Q. (2014). Sexual discretion: Black masculinity and the politics of passing. Chicago, IL: University of Chicago Press.

Miller, P. R., Flores, A. R., Haider-Markel, D. P., Lewis, D. C., Tadlock, B. L., \& Taylor, J. K. (2017). Transgender politics as body politics: Effects of disgust sensitivity and authoritarianism on transgender rights attitudes. Politics, Groups, and Identities, 5(1), 4-24.

Moran, L. J., \& Sharpe, A. N. (2004). Violence, identity and policing: The case of violence against transgender people. Criminology \& Criminal Justice, 4(4), 395-417.

Moriel, L. (2005). Passing and the performance of gender, race, and class acts: A theoretical framework. Women $\&$ Performance, 15(1), 167-210.

Moynihan, S. (2010). Passing into the present: Contemporary American fiction of racial and gender passing. Manchester, UK: Manchester University Press.

Nagoshi, J. L., Adams, K. A., Terrell, H. K., Hill, E. D., Brzuzy, S., \& Nagoshi, C. T. (2008). Gender differences in correlates of homophobia and transphobia. Sex Roles, 59(7-8), 521-531.

Raymond, J. (1979). The transsexual empire: The making of the she-male. Boston, MA: Beacon Press.

Riddell, C. (2006). Divided sisterhood: A critical review of Janice Raymond's The Transsexual Empire. In S. Stryker \& S. Whittle (Eds.), The transgender studies reader (pp. 144-158). New York, NY: Routledge.

Robinson, A. (1994). It takes one to know one: Passing and communities of common interest. Critical Inquiry, 20(4), 715-736.

Roen, K. (2002). "Either/or" and "both/neither": Discursive tensions in transgender politics. Signs, $27(2), 501-522$.

Rogers, M. F. (1992). They were all passing: Agnes, Garfinkel, and company. Gender \& Society, $6(2), 169-191$.

Rottenberg, Catherine. (2003). Passing: Race, identification, and desire. Criticism, 45 (4), 435-452.

Schilt, K., \& Westbrook, L. (2009). Doing gender, doing heteronormativity: "Gender normals," transgender people, and the social maintenance of heterosexuality. Gender 83 Society, 23(4), 
$440-464$.

Serano, J. (2007). Whipping girl: A transsexual woman on sexism and the scapegoating of femininity. Emeryville, CA: Seal Press.

Sims, A. (2016, June 11). Trans people could 'face rape charges' if they don't declare sexual history, warns trans activist. Independent. Retrieved from http://www.independent.co.uk/news/uk/homenews/trans-people-could-face-rape-charges-if-they-don-t-declare-sexual-history-warns-trans-activista7076546.html

Sloop, J. M. (2000). Disciplining the transgendered: Brandon Teena, public representation, and normativity. Western Journal of Communication, 64(2), 165-189.

Snorton, C. R. (2009). "A new hope": The psychic life of passing. Hypatia, 24(3), 77-92.

Squires, C. R., \& Brouwer, D. C. (2002). In/discernible bodies: The politics of passing in dominant and marginal media. Critical Studies in Media Communication, 19(3), 283-310.

Stone, S. (1994). The empire strikes back: A posttransexual manifesto. Camera Obscura, 29, $150-176$

Stotzer, R. L. (2009). Violence against transgender people: A review of United States data. Aggression and Violent Behavior, 14(3), 170-179.

Tilleman, M. (2010). (Trans)forming the provocation defense. Journal of Criminal Law and Criminology, $100(4), 1659-1688$.

West, C., \& Zimmerman, D. H. (1987). Doing gender. Gender \& Society, 1(2), 125-151.

Westbrook, L., \& Schilt, K. (2014). Doing gender, determining gender: Transgender people, gender panics, and the maintenance of the sex/gender/sexuality system. Gender $\mathscr{G}$ Society, 28(1), $32-57$.

Wickes, R., \& Emmison, M. (2007). They are all "doing gender" but are they are all passing? A case study of the appropriation of a sociological concept. The Sociological Review, 55(2), 311-330.

Wilchins, R. A. (2006). What does it cost to tell the truth? In S. Stryker \& S. Whittle (Eds.), The transgender studies reader (pp. 547-551). New York, NY: Routledge.

Willox, A. (2003). Branding Teena: (Mis)representations in the media. Sexualities, 6(3-4), 407-425.

Wodda, A., \& Panfil, V. R. (2015). Don't talk to me about deception: The necessary erosion of the trans* panic defense. Albany Law Review, 78(3), 927-971.

Zimmerman, D. H. (1992). They were all doing gender, but they weren't all passing: Comment on Rogers. Gender \&3 Society, 6(2), 192-198. 